Article

\title{
Sustainability Assessment during Machining Ti-6Al-4V with Nano-Additives-Based Minimum Quantity Lubrication
}

\author{
Hossam A. Kishawy ${ }^{1}$, Hussien Hegab ${ }^{1, *}$, Ibrahim Deiab ${ }^{2}$ (D) and Abdelkrem Eltaggaz ${ }^{2}$ \\ 1 Machining Research Laboratory, Ontario Tech University, Oshawa, ON, L1G 0C5, Canada \\ 2 Advanced Manufacturing Laboratory, University of Guelph, Guelph, ON, N1G 2W1, Canada \\ * Correspondence: Hussien.Hegab@uoit.ca
}

Received: 10 June 2019; Accepted: 22 July 2019; Published: 24 July 2019

\begin{abstract}
The implementation of sustainable machining process can be accomplished by different strategies including process optimization and selection of the proper lubrication techniques and cutting conditions. The present study is carried out from the perspective of a sustainability assessment of turning Ti-6Al-4V by employing minimum quantity lubrication (MQL) and MQL-nanofluid with consideration of the surface quality, tool wear, and power consumption. A sustainability assessment algorithm was used to assess the cutting processes of Ti-6Al-4V alloy under a minimum quantity of lubrication-nanofluid to estimate the levels of sustainable design variables. The assessment included the sustainable indicators as well as the machining responses in a single integrated model. The sustainable aspects included in this study were; environmental impact, management of waste, and safety and health issues of operators. The novelty here lies in employing a comprehensive sustainability assessment model to discuss and understand the machining process with MQL-nanofluid, by not only considering the machining quality characteristics, but also taking into account different sustainability indicators. In order to validate the effectiveness of the sustainability results, a comparison between the optimal and predicted responses was conducted and a good agreement was noticed. It should be stated that MQL-nanofluid showed better results compared to the cutting tests conducted under using classical MQL.
\end{abstract}

Keywords: machining; sustainability; minimum quantity lubrication; nano-additives; assessment

\section{Introduction}

The constant pressure on the manufacturers to innovate and implement sustainable processes has triggered researching on machining with low carbon footprint, minimum energy consumption by machine tools and improved products at the lowest cost. From the past few decades, there is an immense increase in energy consumption in the manufacturing sector. Determination of the ideal machining parameters for machine tools is an important issue in order to diminish energy utilization and ecological discharges [1]. A previous study [2], documented that the energy consumption by the industrial sector has been doubled compared to the past 80 years. The utilization of raw materials such as wood, aluminum, zinc, steel, and copper has tremendously increased in the field of manufacturing. The speedy development in the manufacturing of these raw materials has given rise to many problems such as social, economic and environmental problems that in turn enhanced global warming and waste disposal [3]. Therefore, there is a vast need for a reduction in use of energy, material consumption and pollution by improving manufacturing performances. In machining processes, different attempts [4-11] have been performed to optimize and assess the cutting performance behavior in order to reach sustainable environment which offers better tool life and machinability. Cutting 
fluids are one of the most important factors to be considered in machine operation to provide a longer tool life and ease the processing. The main objective of the cutting fluids is to reduce workpiece and tool temperature by lowering the coefficient of friction between chips and tools [12]. Previous studies $[13,14]$ conducted several experiments with focus on the effects of material and tool and cutting conditions in the turning of AISI 1045 steel and concluded that the use of fluid while turning has a tremendous impact on tool life as it lasts longer compared to dry cutting. Many researchers [15-18] used a green cutting technology known as minimal quantity lubricant where air is compressed and spurted into cutting region, so that the temperature and friction is reduced near the interface of the tool and chip, which in turn enhances the quality of the machining surface and increases the tool life. However, another work [19] indicated that green cutting is not an effective technique when enormous heat generation takes place as higher efficiency becomes a prominent factor in the metal cutting process. In this regard, the metal removal rate is rapidly increasing. Nonetheless, the increase in this parameter depletes the cutting tool life as elevated heat and friction are obtained at the cutting area. Therefore, an improved minimum quantity lubrication (MQL) has to be developed with higher lubrication and cooling capabilities.

Recent studies [20-25] proved that nano-fluids have a remarkable impact in reducing friction and heat when compared with the conventional fluid. Hegab et al. [21] employed MWCNTs nanofluid when machining Inconel 718, and better results were obtained compared to classical MQL. In addition, $\mathrm{MoS}_{2}$ MQL-nanofluid [26] was used when grinding 45 Steel, and it improved the resultant surface quality because of the promising lubrication performance. A recent study [27] has presented a comparative analysis between different cooling and lubrication strategies (i.e., dry cutting, cryogenic, MQL, nanofluid, and MQL-nanofluid). The analysis was mainly based on studying the sustainability effectiveness in terms of waste management, environmental impact, energy consumption and safety. Alternatively, the use of minimum quantity lubricant (MQL) reduces the cutting fluid quantity during machining $[28,29]$. However, when machining difficult-to-cut materials, MQL is not a proper alternative of the flood coolant. Ti-6Al-4V is among these materials which have different cutting problems (e.g., heat disputation and tool wear). Thus, presenting effective cooling and lubrication techniques is required to face such problems. Recently [30], a new hybrid cryogenic MQL cooling and lubrication system was proposed and tested for machining Ti-6Al-4V titanium alloy. The proposed techniques offered a 30-time increase in tool life in end milling Ti-6Al-4V alloy compared to flood machining. In addition, to enhance the wettability and fluid thermal aspects, MQL nano-fluid approach has been used [31,32]. The nano-additives such as aluminum oxide $\left(\mathrm{Al}_{2} \mathrm{O}_{3}\right)$ gamma nanoparticles have superior cooling and lubrication properties. The effect of the nano-fluids technology on the performance of machining processes has been studied in several articles. For example, the nano-diamond particles were dispersed in paraffin and vegetable oils under MQL during micro drilling of aluminum 6061 [33]; aluminum oxide-based nano-fluid has been used in micro-grinding of tool steel [34]; and MQL-nano-fluid with chilly $\mathrm{CO}_{2}$ gas was implemented during micro-end-milling of Ti-6Al-4V [35]. In this work, a previous assessment algorithm [36] was used to assess the cutting processes of Ti-6Al-4V alloy under MQL-nanofluid approach to estimate the levels of sustainable design variables, while considering sustainable indicators as well as the machining responses (i.e., flank wear (VB), power consumption, and average surface roughness (Ra)). This algorithm concentrates on the three major aspects of sustainability namely economic, environmental, and societal. The novelty here lies on employing a comprehensive sustainability assessment model to discuss and understand the machining process with MQL-nanofluid, by not only by considering the machining quality characteristics, but also considering different sustainability indicators. The combined effect can be easily obtained by determining a total weighted sustainable index (higher-the-better).

\section{Experimentation and Methods}

The machining tests were conducted for Ti-6Al-V4 alloy using the vegetable oil based MQL-nanofluid coolant. The length of each cutting pass was $50 \mathrm{~mm}$ with a depth of cut of $0.5 \mathrm{~mm}$. 
Through the using of an MQL system, an Eco-Lubric booster system supplied an air-oil mist with $0.5 \mathrm{MPa}$ air pressure and $40 \mathrm{~mL} / \mathrm{h}$ nominal oil flow rate. The experimental setup view including machine tool, cutting insert, MQL nozzle, and workpiece is provided in Figure 1. In this section, the $\mathrm{Al}_{2} \mathrm{O}_{3}$ nanoparticles with a $22 \mathrm{~nm}$ average diameter, $134 \mathrm{~m}^{2} / \mathrm{g}$ specific surface areas, $92 \%$ purity were used as a nano-additives due to its great tribological property and anti-toxic aspect (see Figure 2). However, the dispersion of nanoparticles into the oil base fluid is challenging due to microscopic forces that are applied on nanoparticles. These forces, such as gravity force, van der Waals dispersion forces, and density difference, promote sedimentation and nanoparticle agglomeration [37]. Through the use and installation of a stand-alone booster system (Eco-Lubric) onto the machine tool, an air-oil mixture offered a nominal flow rate of $40 \mathrm{~mL} / \mathrm{h}$ and air pressure of $0.5 \mathrm{MPa}$. In addition, ECOLUBRIC E200 was employed as a vegetable oil used for experimentation. This is a cold-pressed rapeseed oil type without additives. The dispersion of nanoparticles into the base oil is crucial because it affects the viscosity and thermal conductivity of the resultant nanofluid-MQL. In this regard, a chemical or physical treatment was used, such as surfactants, to promote a sufficient dispersion of nanoparticles [38,39]. Sodium Dodecyl Sulfate (SDS) was utilized as a surfactant $(0.2 \mathrm{~g})$. Surfactants are believed to make the nanoparticle performance more hydrophilic, and to increase the surface charges of the nanoparticles, thereby increasing the repulsive forces between the nanoparticles $[40,41]$. In order to evaluate the agglomerate of nanoparticles into the MQL-nanofluid, Zeta potential for stability analysis was also conducted. The Zetasizer nano-device was employed to estimate the zeta potential absolute values for nanofluids with two $\mathrm{Al}_{2} \mathrm{O}_{3}$ concentrations. The larger the value of the Zeta potential absolute, the better the dispersion of $\mathrm{Al}_{2} \mathrm{O}_{3}$ nanoparticles and a modeled level of zeta potential has been noticed. Zeta values for $2 \mathrm{wt}$. \% and $4 \mathrm{wt}$. \% are 29 and 25, respectively, and these values showed a moderate stability for the proposed nanofluids according to a previous study [42]. The tests were performed on a CNC lathe machine (Hass ST-10 CNC) using standard carbide turning inserts and tool holders (i.e., $\mathrm{CNMG}$ 120416MR ISO). In order to investigate the effects of MQL- $\mathrm{Al}_{2} \mathrm{O}_{3}$ performance, different orthogonal cutting trials for Ti-6Al-4V were performed with/without nano-additives. A constant depth of cut of $0.2 \mathrm{~mm}$ was used, where the cutting length was $50 \mathrm{~mm}$ per each cutting pass. Different experiments were performed using MQL at different levels of speed, feed rate, and added nano-additive concentrations. Power sight manager device was utilized throughout the cutting operation to assist in recording the power consumption. This device is a powerful tool that can be easily and reliably installed and operated into the machine tool through 3-phases module. It is mainly based on measuring the total power including active and re-active components. In addition, it is connected to an online monitoring program. Flank wear and surface roughness data were obtained subsequent to each machining pass, using a surface roughness tester and an optical microscope, respectively. Regarding the tool wear measurements, a maximum flank wear (VB) of $0.4 \mathrm{~mm}$ was used as the tool life criteria otherwise, in the case of not reaching the end-of-tool-life criteria, the cutting stopped after nine cutting passes. The average surface roughness Ra was commonly recognized, and the most-used parameter to evaluate the machined surface roughness. The used cut-off length is $0.8 \mathrm{~mm}$. After each cutting test, the surface roughness tester is used in five random regions along the machined surface, and the average value is considered. The cutting tests are replicated three times and the average response value is calculated. In this work, MQL nanofluid with different concentrations of weight fraction (i.e., 0,2 , and 4 wt. \%), various cutting speeds (i.e., 120,170 , and $220 \mathrm{~m} / \mathrm{min}$ ) and feed rates (i.e., $0.1,0.15$, and $0.2 \mathrm{~mm} / \mathrm{rev}$ ) were selected as design variables for machining Ti-6Al-4V titanium alloy. During the experimentation phase, certain safety procedures (i.e., standard nano-additives safety data sheets) have been applied to maintain a standard health and safety level in the workshop to avoid any harmful impacts for the machine operator. Regarding the disposal method, the nano-fluids have been carefully filtered before being released to the sewer according to a standard material safety data sheet [43]. In this study, three design parameters were selected with three levels each. The orthogonal array L9 Taguchi method (L9OA) was applied during the cutting experiments as shown in Table 1. The full factorial array is supposed to be L27OA; however, L9OA has been used instead to save time and cost. 
Also, it should be stated that many cutting studies [21,22] have been previously applied L9OA for design of experiments, and it showed reasonable results.

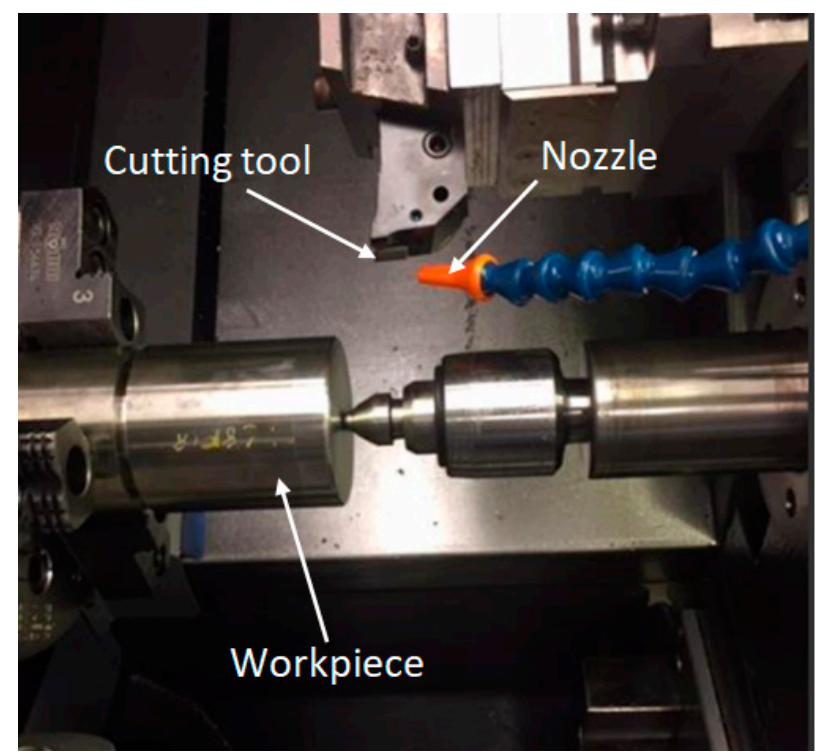

Figure 1. Experimental setup view.
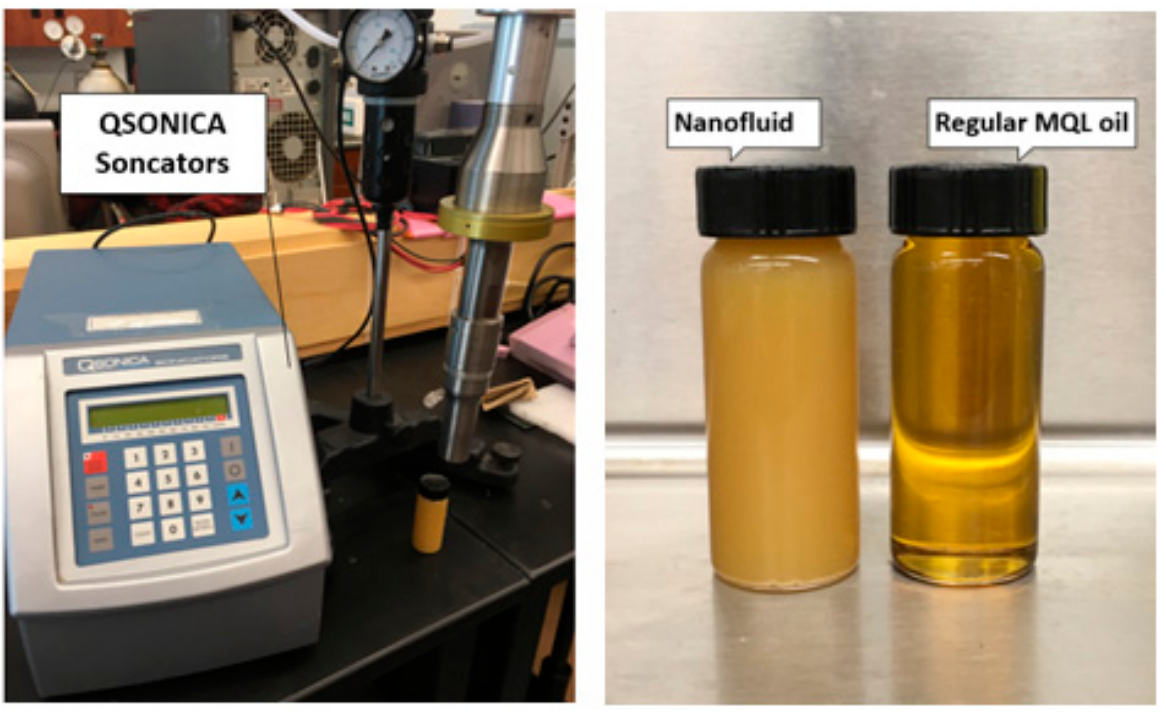

Figure 2. Images of (left side) an AQUASONIC-50HT device used to achieve the dispersion; and (right side) a classical minimum quantity lubrication (MQL) and MQL-nanofluid $\left(\mathrm{Al}_{2} \mathrm{O}_{3}\right.$-based).

Table 1. L9 Taguchi method (L9OA) for design of experiments.

\begin{tabular}{cccc}
\hline Experiment No. & $\begin{array}{c}\text { A: Cutting Speed } \\
(\mathbf{m} / \mathbf{m i n})\end{array}$ & $\begin{array}{c}\text { B: Feed Rate } \\
(\mathbf{m m} / \mathbf{r e v})\end{array}$ & $\begin{array}{c}\text { C: Nanoparticles } \\
\text { Concentration (wt. \%) }\end{array}$ \\
\hline 1 & 120 & 0.1 & 0 \\
2 & 120 & 0.15 & 2 \\
3 & 120 & 0.2 & 4 \\
4 & 170 & 0.1 & 2 \\
5 & 170 & 0.15 & 4 \\
6 & 170 & 0.2 & 0 \\
7 & 220 & 0.1 & 4 \\
8 & 220 & 0.15 & 0 \\
9 & 220 & 0.2 & 2 \\
\hline
\end{tabular}




\section{Experimental Results}

The current work records the findings with regards to maximum flank wear in the tool (VB), surface roughness $(\mathrm{Ra})$, and power consumption. Table 2 describes the results for the machining quality characteristics that were studied. The flank wear varied from 0.162 to $0.561 \mathrm{~mm}$, and the surface roughness varied from 0.512 to $2.81 \mu \mathrm{m}$. In terms of the power consumption, the results varied from 1959 to $2634 \mathrm{~W}$. In terms of tool wear, the lowest maximum flank wear (VB) was observed at a speed of $120 \mathrm{~m} / \mathrm{min}$, a feed rate of $0.2 \mathrm{~mm} / \mathrm{rev}$, and a nanoparticle concentration of $4 \mathrm{wt}$. \%. The speed significantly affected the tool wear due to high heat generated in the cutting zone. Additionally, the nanoparticle concentration was found to affect the tool wear performance. This effect on tool wear was likely due to the worthy thermal conductivity of the nanoparticle being used and its ability to penetrate the chip/workpiece zone. Consequently, the MQL nanofluid effect supports enhancement of the machining performance, the viscous property, and the heat removal ability of the nanofluid as discussed in some previous studies [44-46]. Based on the provided results (see Table 2), the lowest surface roughness was noted at a feed rate of $0.1 \mathrm{~mm} / \mathrm{rev}$, a cutting speed of $170 \mathrm{~m} / \mathrm{min}$, and a nanoparticle concentration of $2 \mathrm{wt}$. \%. Feed rate and nanoparticles wt. \% were found to have the highest impact on the surface roughness quality. It is known that the feed rate has a significant effect on the surface roughness in machining processes. In addition, the impact of an increase in nanoparticle concentration can be attributed to the increase in nanoparticles, which can penetrate the chip and workpiece surface and settle in any micro-grooves or slits. This is known as the surface protective effect of nano-mist [47]. Regarding the power consumption results, the lowest power consumption was obtained at a feed rate of $0.2 \mathrm{~mm} / \mathrm{rev}$, a cutting speed of $170 \mathrm{~m} / \mathrm{min}$, and a nanoparticle concentration of $4 \mathrm{wt}$. \%. Feed rate and nanoparticle wt. \% were found to have the highest impact on the measured power consumption. It was noted that increasing the nanoparticle concentrations played a vital role in decreasing the induced friction as the nanoparticles act as spacers at the tool-workpiece contact, and therefore significantly affect the measured power consumption. In addition to the previous results, some SEM images was captured with MQL-nanofluid (2 wt. \%) and without MQL (classical) at cutting speed of $170 \mathrm{~m} / \mathrm{min}$ and feed rated of $0.15 \mathrm{~mm} / \mathrm{rev}$. Figure 3 shows the tool wear mechanisms for the two scenarios. Generally, in both cases, a spot of abrasion was detected on the flank face due to a rubbing between the cutting tool and workpiece at tool-workpiece interface. Figure $3 b$ shows the condition of the cutting tool after using classical MQL. The results show that an extreme abrasion wear with relatively small adhesion on flank face tool wear. The flank wear is mostly due to the abrasion wear, since the hard particles in the material rub against the tool surface. Additionally, during chip deformation, the flowing chips take off particles from the contact zone of the tool. This action is responsible for causing flank wear and effecting tool life. Regarding the MQL nanofluid effect, a noticeable improvement can be seen in Figure 3a in terms of crater wear and flank wear. It is mainly attributed to the effective tribological and heat transfer properties of the nano mist which improve the heat transfer and frictional behavior as has been discussed by Hegab et al [44].

Table 2. Experimental results.

\begin{tabular}{cccc}
\hline Experiment No. & $\begin{array}{c}\text { Surface } \\
\text { Roughness }(\boldsymbol{\mu m})\end{array}$ & $\begin{array}{c}\text { Max Flank } \\
\text { Wear }(\mathbf{m m})\end{array}$ & $\begin{array}{c}\text { Power } \\
\text { Consumption }(\mathbf{W})\end{array}$ \\
\hline 1 & 0.891 & 0.236 & 2325 \\
2 & 0.852 & 0.165 & 2041 \\
3 & 1.692 & 0.162 & 1959 \\
4 & 0.512 & 0.192 & 2079 \\
5 & 1.421 & 0.153 & 2106 \\
6 & 2.812 & 0.563 & 2454 \\
7 & 0.563 & 0.180 & 2084 \\
8 & 1.890 & 0.561 & 2634 \\
9 & 0.951 & 0.242 & 2236 \\
\hline
\end{tabular}



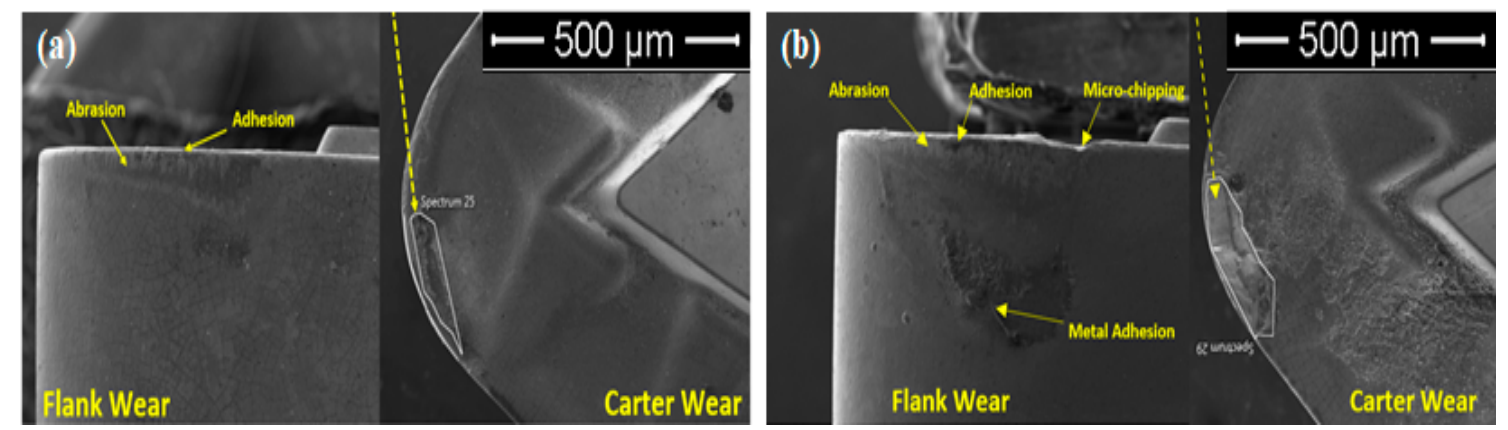

Figure 3. Tool wear mechanisms with MQL nanofluid (a) with classical MQL (b) at a cutting speed of $170 \mathrm{~m} / \mathrm{min}$ and feed rate of $0.15 \mathrm{~mm} / \mathrm{rev}$.

\section{Sustainability Assessment}

Sustainable manufacturing is defined as "the creation of manufactured products using processes that minimize negative environmental impacts, conserve energy and natural resources, are safe for employees, communities, and consumers, and are economically sound". The implementation of sustainable machining processes can be achieved by different strategies including process optimization, selection of the proper lubrication techniques, tool material and coating in addition to employing hybrid machining process. These strategies are implied to achieve cost reduction, energy efficiency, waste reduction and management, health and safe operation, resource efficiency, and green environment as shown in Figure 4 [48].

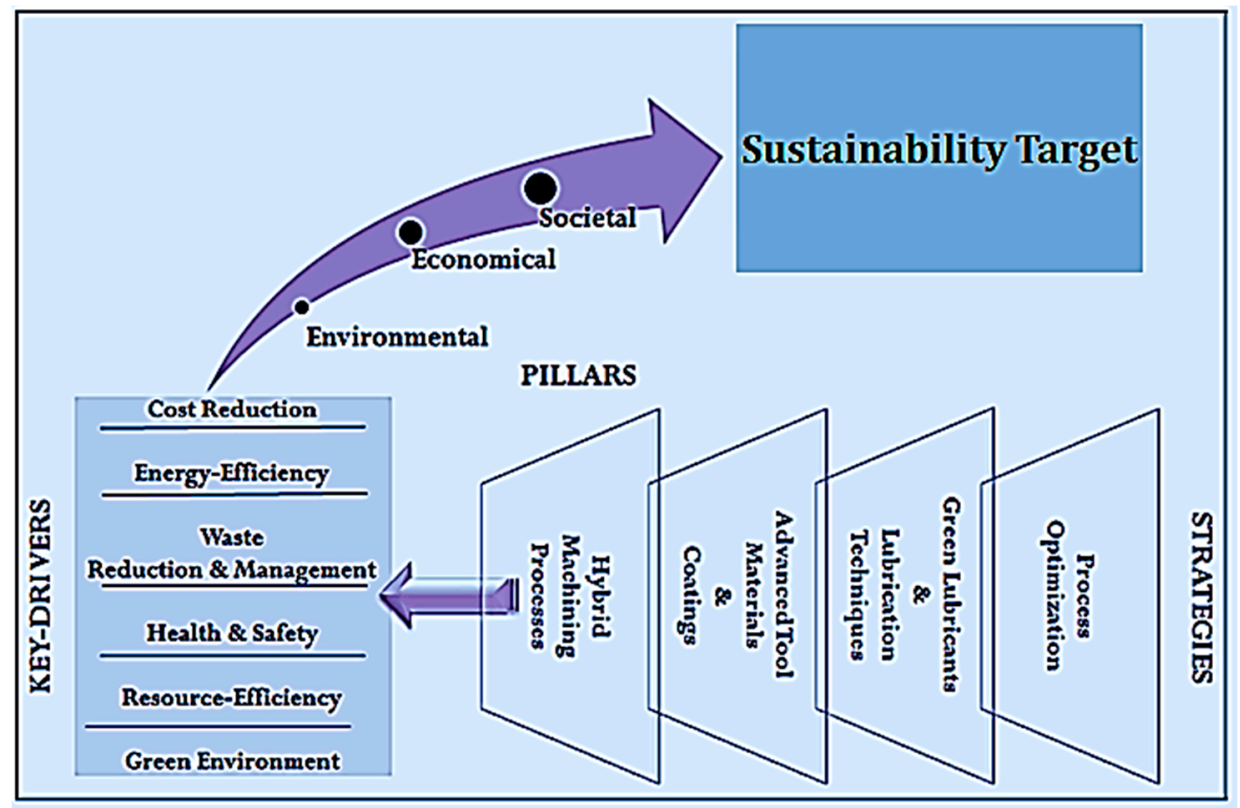

Figure 4. Sustainable manufacturing: strategies, targets, and pillars.

It is essential to consider the sustainability aspects during machining processes in order to achieve optimal and sustainable cutting conditions. In this work, the sustainability assessment model of Hegab et al. [36] is employed to obtain the optimal design variables levels (i.e., based on both cutting responses as well as sustainability performance). The predicted/optimal values consider the machining outputs (i.e., surface quality, flank wear, and power consumption) as well as the performance indicators of the main sustainability pillars (i.e., environmental impact, waste management, and safety and health aspects). In this study, $E_{n e}$ is the environmental performance indicator which shows the carbon dioxide emissions according to the power consumed in each cutting test using a standard defined 
emission intensity [34]. Regarding the personal health and operation safety, the selected sustainable indicators are the high-speed surface exposure $\left(\mathrm{OS}_{\mathrm{hss}}\right)$ and the toxic chemicals exposure $\left(\mathrm{O}_{\mathrm{Stc}}\right)$, which are lower-the-better indicators. SS $_{\text {hss }}$ values have been set as " 1 " at cutting speed of $120 \mathrm{~m} / \mathrm{min}$, "2" for $170 \mathrm{~m} / \mathrm{min}$, and " 3 " at cutting speed of $220 \mathrm{~m} / \mathrm{min}$. In this work, equally weighting factors were employed for all sustainable indicators as well as the measured machining outputs. $\mathrm{OS}_{\mathrm{tc}}$ values were set as " 1 " for MQL cutting tests, and "2" for MQL-nanofluid tests. In terms of the waste management, the amount of coolant has been used $\left(\mathrm{W}_{\mathrm{f}}\right)$, where $\mathrm{W}_{\mathrm{f}}$ values have been set as " 1 " for MQL cutting tests, and "2" for MQL-nanofluid tests. It should be stated that both $\mathrm{OS}_{\mathrm{tc}}$ and $\mathrm{W}_{\mathrm{f}}$ have been selected based on the sustainable guideline for machining operation presented by Hegab et al. [36]. The sustainability assessment steps are summarized as following:

- Selecting and defining the studied sustainable metrics and their corresponding indictors

- Normalizing/scaling the studied machining outputs, and sustainability metrics and indicators

- Weighting of normalized factors

- Calculating the overall sustainability assessment index (TWSI).

The main steps [36] used to represent the overall sustainability index in order to assess the whole machining system in terms of the studied machining metrics, indicators, and machining responses are included in Figure 5. The overall sustainability index is between 0 and 1, where higher indices mean better sustainable performance. The overall sustainability assessment index for each run has been calculated based on all previous considerations. The sustainability assessment results are provided as shown in Figure 6. As can be seen in Figure 6, the cutting test \#4 shows the highest performance, this test has been performed at cutting speed of $170 \mathrm{~m} / \mathrm{min}$, feed rate of $0.1 \mathrm{~mm} / \mathrm{rev}$, and $2 \mathrm{wt}$. \% of added $\mathrm{Al}_{2} \mathrm{O}_{3}$. Regarding the lowest performance, it has been found at cutting test\#8. Test\#8 has been conducted at cutting speed of $220 \mathrm{~m} / \mathrm{min}$, feed rate of $0.15 \mathrm{~mm} / \mathrm{rev}$, and using classical MQL (i.e., 0 wt. $\%$ of added $\mathrm{Al}_{2} \mathrm{O}_{3}$ ). Regarding the optimal levels of the nano-additives concentration, it has been found that $4 \mathrm{wt}$. \% for the best experimentally surface quality and tool performance, and lowest power consumption. However, the assessment model showed that cutting test 4 is the optimal test which has the highest total weighted index. The nano-additives concentration at this test is $2 \mathrm{wt}$. \%. It is mainly because this assessment model is focused on establishing a balance between the machining outputs and the studied sustainability aspects. At this point, the experimental investigations were not the same as the assessment model findings; however, the model finding provides more physical sense as the highest percentage of nano-additive ( $4 \mathrm{wt}$. \%) could cause more deteriorations to the cutting processes because of the highest occurrence possibility of the drastic ploughing effects which could increase the induced nano-additives wear and accordingly increase the overall tool wear. When there is an abundance of nano-additives in the resultant nano-fluid, they collide with and are impeded by the asperities on the work surface and hence generate stronger cutting forces. As a result, the nano-additive induced wear is increased with increasing the nano-additives concretion as similarly discussed in a previous work [49].

In order to validate the effectiveness of the employed assessment model, a comparison between the optimal and predicted responses values (surface roughness, tool wear, and power consumption) was established as can be seen in Figure 7. The experimental values in Figure 7 refer to the optimal machining responses obtained at Table 2. On the other hand, the predicted values refer to the machining responses at cutting test\#4 in which the highest total-weighted sustainable index has been found. It should be stated that identical values were observed between the predicted and optimal values in terms of the surface roughness results (see Figure $7 \mathrm{~b}$ ). Regarding the power consumption and flank wear, a good agreement (i.e., average accuracy of $94.3 \%$ and $75 \%$, for both power consumption and flank wear, respectively) was noticed as can be seen in Figure $7 \mathrm{a}, \mathrm{c}$ as this assessment model is mainly focused on establishing a balance between the machining outputs and the studied sustainability aspects, and it is a valuable tool to optimize the machining processes performance with considering the sustainability effectiveness as previously discussed in the open literature [36]. The implemented model 
and associated results are mainly based on combining the machining performance and sustainability indicators in an integrated index (higher-the-better). It should be stated that both Figures 6 and 7 confirm that MQL-nanofluid offers the best performance in terms of machining outputs as well as sustainability aspects.

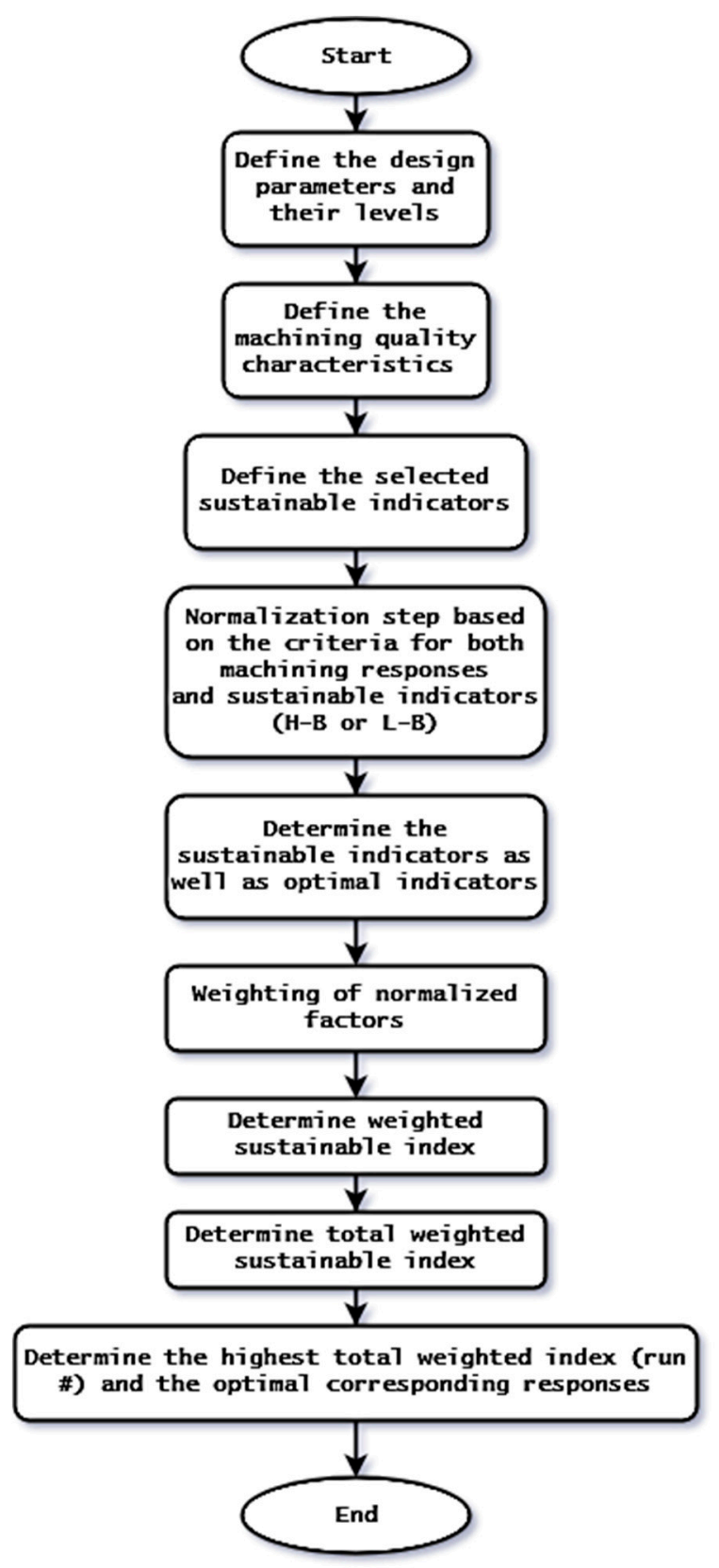

Figure 5. A flow chart for the sustainability assessment model [36]. 


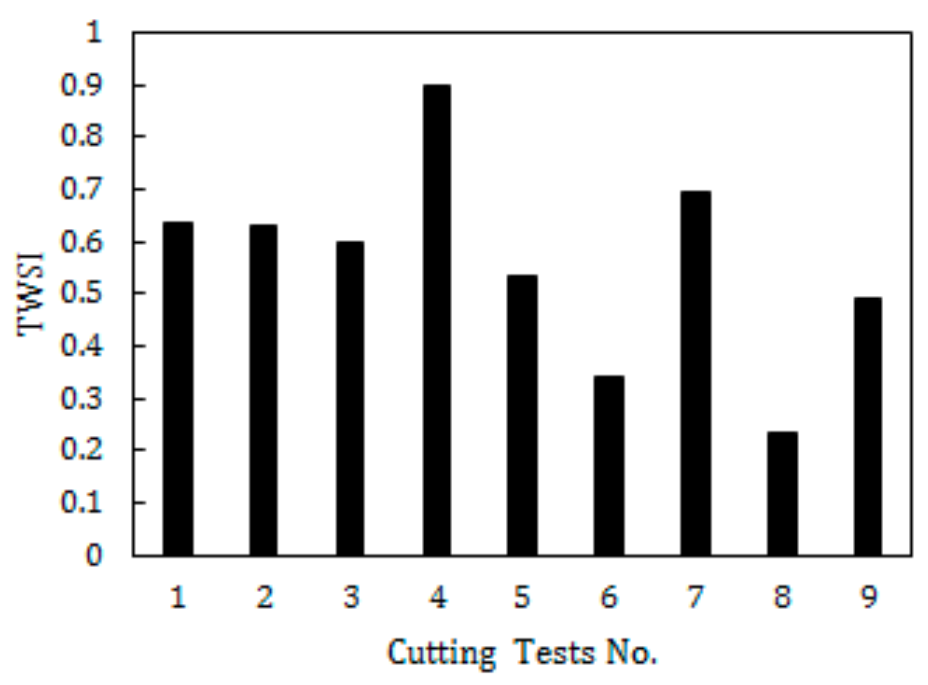

Figure 6. The sustainability assessment results.

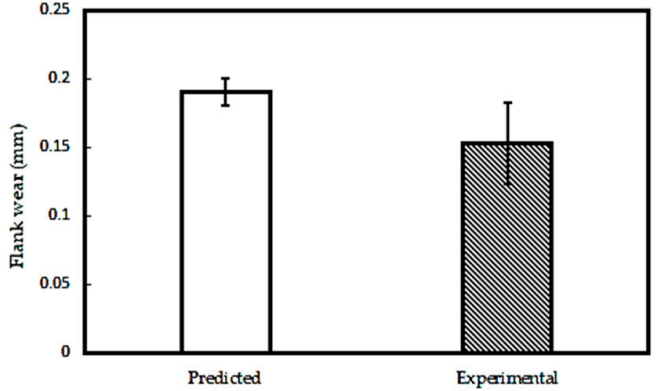

(a)

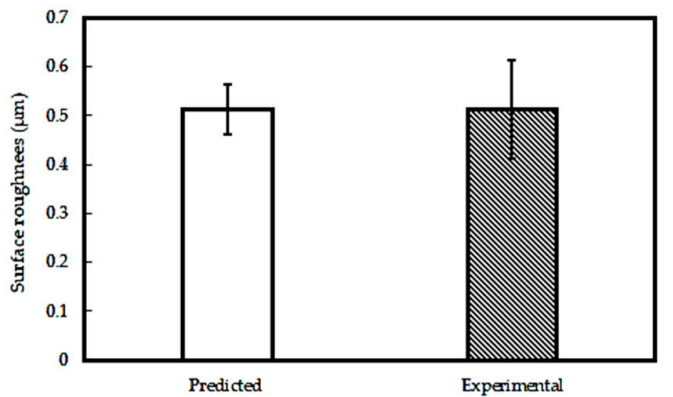

(b)

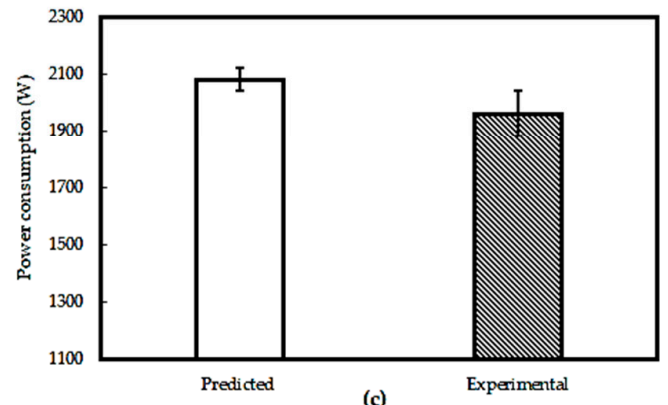

Figure 7. A comparison between the predicted and experimental results: (a) flank wear; (b) surface roughness; and (c) power consumption.

\section{Conclusions and Future Work}

The present study is carried out from the perspective of sustainability assessment of turning Ti-6Al-4V by employing MQL and MQL-nanofluid with consideration of the surface quality, tool wear, and power consumption. Additional considerations were included, such as the environmental impact, management of waste, and safety and health issues of operators. In terms of tool wear, the lowest maximum flank wear (VB) was observed at a speed of $120 \mathrm{~m} / \mathrm{min}$, a feed rate of $0.2 \mathrm{~mm} / \mathrm{rev}$, and a nanoparticle concentration of $4 \mathrm{wt}$. \%. The lowest surface roughness was noted at a feed rate of $0.1 \mathrm{~mm} / \mathrm{rev}$, a cutting speed of $170 \mathrm{~m} / \mathrm{min}$, and a nanoparticle concentration of $2 \mathrm{wt}$. \%. Feed rate and nanoparticles wt. \% were found to have the highest impact on the surface roughness quality. Regarding the power consumption results, the lowest power consumption was obtained at a feed rate of $0.2 \mathrm{~mm} / \mathrm{rev}$, a cutting speed of $170 \mathrm{~m} / \mathrm{min}$, and a nanoparticle concentration of $4 \mathrm{wt}$. \%. Similarly, to the surface roughness results, the feed rate and nanoparticle wt. \% were found to have the highest impact 
on the measured power consumption. In order to assess the cutting process from the sustainability point of view, a comprehensive assessment model was used. This model was based on combining the machining performance and sustainability indicators in an integrated index (higher-the-better). Regarding the sustainability assessment results, the cutting test \#4 shows the highest performance, this test has been performed at cutting speed of $170 \mathrm{~m} / \mathrm{min}$, feed rate of $0.1 \mathrm{~mm} / \mathrm{rev}$, and $2 \mathrm{wt}$. \% of added $\mathrm{Al}_{2} \mathrm{O}_{3}$. The lowest performance, it has been found at cutting test\#8. Test\#8 was conducted at a cutting speed of $220 \mathrm{~m} / \mathrm{min}$, feed rate of $0.15 \mathrm{~mm} / \mathrm{rev}$, and using classical MQL (i.e., 0 wt. \% of added $\mathrm{Al}_{2} \mathrm{O}_{3}$ ). In order to validate the effectiveness of the sustainability results, a comparison between the optimal and predicted responses values showed a good agreement was noticed. It is worth mentioning that the findings confirm that MQL-nanofluid offers the best performance in terms of machining outputs as well as sustainability aspects. In terms of future work, more details should be considered to include the interactional effects of the studied sustainable indicators. In addition, a sensitivity performance analysis was performed to assign different weighting factors for both machining outputs and sustainability indicators. Furthermore, another power element related to the dispersion and delivery of nano-mist should be considered in the future to make this study more effective in terms of sustainability assessment.

Author Contributions: H.H. and A.E. designed, performed relevant experiments and wrote the manuscript; H.A.K. and I.D. supervised the experiments and data analysis, and reviewed the manuscript.

Funding: The authors would like to thank the Natural Sciences and Engineering Research Council of Canada (NSERC), and the Ontario Centers of Excellence (OCE) for funding this research work.

Conflicts of Interest: The authors declare no conflict of interest.

\section{References}

1. Garg, G.K.; Garg, S.; Sangwan, K. Development of an Empirical Model for Optimization of Machining Parameters to Minimize Power Consumption. IOP Conf. Ser. Mater. Sci. Eng. 2018, 346, 012078. [CrossRef]

2. Fang, K.; Uhan, N.; Zhao, F.; Sutherland, J.W. A new approach to scheduling in manufacturing for power consumption and carbon footprint reduction. J. Manuf. Syst. 2011, 30, 234-240. [CrossRef]

3. Sangwan, K.S. Development of a multi criteria decision model for justification of green manufacturing systems. Int. J. Green Econ. 2011, 5, 285-305. [CrossRef]

4. Hosseini, A.; Kishawy, H.A. Cutting tool materials and tool wear. In Machining of Titanium Alloys; Springer: Berlin/Heidelberg, Germany, 2014; pp. 31-56.

5. Kishawy, H.A.; Pang, L.; Balazinski, M. Modeling of tool wear during hard turning with self-propelled rotary tools. Int. J. Mech. Sci. 2011, 53, 1015-1021. [CrossRef]

6. Hegab, H.A.; Gadallah, M.H.; Esawi, A.K. Modeling and optimization of Electrical Discharge Machining (EDM) using statistical design. Manuf. Rev. 2015, 2, 21. [CrossRef]

7. Kishawy, H.A.; Hegab, H.; Umer, U.; Mohany, A. Application of acoustic emissions in machining processes: analysis and critical review. Int. J. Adv. Manuf. Technol. 2018, 98, 1391-1407. [CrossRef]

8. Kishawy, H.A.; Haglund, A.; Balazinski, M. Modelling of material side flow in hard turning. CIRP Ann. 2006, 55, 85-88. [CrossRef]

9. Kishawy, H.A.; Elbestawi, M.A. Effect of process parameters on chip morphology when machining hardened steel. In Proceedings of the IMECE, ASME, New York, NY, USA, 16-21 November 1997; Volume 6, pp. 13-20.

10. El-Mounayri, H.; Kishawy, H.; Tandon, V. Optimized CNC end-milling: A practical approach. Int. J. Comput. Integr. Manuf. 2002, 15, 453-470. [CrossRef]

11. Fattahi, Z.; Hegab, H.; Kishawy, H.A. Analytical prediction of delamination during drilling composite laminates. Procedia Manuf. 2018, 26, 237-244. [CrossRef]

12. Krolczyk, G.M.; Maruda, R.W.; Krolczyk, J.B.; Wojciechowski, S.; Mia, M.; Nieslony, P.; Budzik, G. Ecological trends in machining as a key factor in sustainable production-A review. J. Clean. Prod. 2019, 218, 601-615. [CrossRef]

13. Diniz, A.E.; de Oliveira, A.J. Optimizing the use of dry cutting in rough turning steel operations. Int. J. Mach. Tools Manuf. 2004, 44, 1061-1067. [CrossRef] 
14. Diniz, A.E.; Micaroni, R. Cutting conditions for finish turning process aiming: the use of dry cutting. Int. J. Mach. Tools Manuf. 2002, 42, 899-904. [CrossRef]

15. Li, K.M.; Chou, S.Y. Experimental evaluation of minimum quantity lubrication in near micro-milling. J. Mater. Process. Technol. 2010, 210, 2163-2170. [CrossRef]

16. Rahim, E.; Sasahara, H. A study of the effect of palm oil as MQL lubricant on high speed drilling of titanium alloys. Tribol. Int. 2011, 44, 309-317. [CrossRef]

17. Dhar, N.; Kamruzzaman, M.; Ahmed, M. Effect of minimum quantity lubrication (MQL) on tool wear and surface roughness in turning AISI-4340 steel. J. Mater. Process. Technol. 2006, 172, 299-304. [CrossRef]

18. Braga, D.U.; Diniz, A.E.; Miranda, G.W.A.; Coppini, N.L. Using a minimum quantity of lubricant (MQL) and a diamond coated tool in the drilling of aluminum-silicon alloys. J. Mater. Process. Technol. 2002, 122, 127-138. [CrossRef]

19. Obikawa, T.; Kamata, Y.; Shinozuka, J. High-speed grooving with applying MQL. Int. J. Mach. Tools Manuf. 2006, 46, 1854-1861. [CrossRef]

20. Eltaggaz, A.; Hegab, H.; Deiab, I.; Kishawy, H.A. Hybrid nano-fluid-minimum quantity lubrication strategy for machining austempered ductile iron (ADI). Int. J. Interact. Des. Manuf. (IJIDeM) 2018, 12, 1273-1281. [CrossRef]

21. Hegab, H.; Darras, B.; Kishawy, H. Sustainability assessment of machining with nano-cutting fluids. Procedia Manuf. 2018, 26, 245-254. [CrossRef]

22. Hegab, H.; Kishawy, H. Towards sustainable machining of Inconel 718 using nano-fluid minimum quantity lubrication. J. Manuf. Mater. Process. 2018, 2, 50. [CrossRef]

23. Jamil, M.; Khan, A.M.; Hegab, H.; Gong, L.; Mia, M.; Gupta, M.K.; He, N. Effects of hybrid $\mathrm{Al}_{2} \mathrm{O}_{3}-\mathrm{CNT}$ nanofluids and cryogenic cooling on machining of Ti-6Al-4V. Int. J. Adv. Manuf. Technol. 2019, 102, 3895-3909. [CrossRef]

24. Hegab, H.; Kishawy, H.A.; Umer, U.; Mohany, A. A model for machining with nano-additives based minimum quantity lubrication. Int. J. Adv. Manuf. Technol. 2019, 102, 2013-2028. [CrossRef]

25. Chatha, S.S.; Pal, A.; Singh, T. Performance evaluation of aluminum 6063 drilling under the influence of nanofluid minimum quantity lubrication. J. Clean. Prod. 2016, 137, 537-545. [CrossRef]

26. Zhang, Y.; Li, C.; Jia, D.; Zhang, D.; Zhang, X. Experimental evaluation of $\mathrm{MoS}_{2}$ nanoparticles in jet MQL grinding with different types of vegetable oil as base oil. J. Clean. Prod. 2015, 87, 930-940. [CrossRef]

27. Hegab, H.; Kishawy, H.; Darras, B. Sustainable Cooling and Lubrication Strategies in Machining Processes: A Comparative Study. Procedia Manuf. 2019, 33, 786-793. [CrossRef]

28. Davim, J.P. Machining of Hard Materials; Springer Science \& Business Media: Berlin/Heidelberg, Germany, 2011.

29. Davim, J.P.; Sreejith, P.; Silva, J. Turning of brasses using minimum quantity of lubricant (MQL) and flooded lubricant conditions. Mater. Manuf. Process. 2007, 22, 45-50. [CrossRef]

30. Shokrani, A.; Al-Samarrai, I.; Newman, S.T. Hybrid cryogenic MQL for improving tool life in machining of Ti-6Al-4V titanium alloy. J. Manuf. Process. 2019, 43, 229-243. [CrossRef]

31. Amrita, M.; Srikant, R.; Sitaramaraju, A. Performance evaluation of nanographite-based cutting fluid in machining process. Mater. Manuf. Process. 2014, 29, 600-605. [CrossRef]

32. Khandekar, S.; Sankar, M.R.; Agnihotri, V.; Ramkumar, J. Nano-cutting fluid for enhancement of metal cutting performance. Mater. Manuf. Process. 2012, 27, 963-967. [CrossRef]

33. Nam, J.S.; Lee, P.H.; Lee, S.W. Experimental characterization of micro-drilling process using nanofluid minimum quantity lubrication. Int. J. Mach. Tools Manuf. 2011, 51, 649-652. [CrossRef]

34. Lee, P.H.; Nam, J.S.; Li, C.; Lee, S.W. An experimental study on micro-grinding process with nanofluid minimum quantity lubrication (MQL). Int. J. Precis. Eng. Manuf. 2012, 13, 331-338. [CrossRef]

35. Kim, J.S.; Kim, J.W.; Lee, S.W. Experimental characterization on micro-end milling of titanium alloy using nanofluid minimum quantity lubrication with chilly gas. Int. J. Adv. Manuf. Technol. 2017, 91, 2741-2749. [CrossRef]

36. Hegab, H.; Darras, B.; Kishawy, H. Towards sustainability assessment of machining processes. J. Clean. Prod. 2018, 170, 694-703. [CrossRef]

37. Dureja, J.; Singh, R.; Singh, T.; Singh, P.; Dogra, M.; Bhatti, M.S. Performance evaluation of coated carbide tool in machining of stainless steel (AISI 202) under minimum quantity lubrication (MQL). Int. J. Precis. Eng. Manuf.-Green Technol. 2015, 2, 123-129. [CrossRef]

38. Klocke, F.; Eisenblätter, G. Dry cutting. Cirp Ann. 1997, 46, 519-526. [CrossRef] 
39. Tschätsch, H.; Reichelt, A. Cutting fluids (coolants and lubricants). In Applied Machining Technology; Springer: Berlin/Heidelberg, Germany, 2009; pp. 349-352.

40. Huang, J.; Wang, X.; Long, Q.; Wen, X.; Zhou, Y.; Li, L. Influence of pH on the stability characteristics of nanofluids. In Proceedings of the 2009 Symposium on Photonics and Optoelectronics, Wuhan, China, 14-16 August 2009; IEEE: New York, NY, USA, 2009.

41. Hwang, Y.J.; Lee, J.K.; Lee, C.H.; Jung, Y.M.; Cheong, S.I.; Lee, C.G.; Ku, B.C.; Jang, S.P. Stability and thermal conductivity characteristics of nanofluids. Thermochim. Acta 2007, 455, 70-74. [CrossRef]

42. Vandsburger, L. Synthesis and Covalent Surface Modification of Carbon Nanotubes for Preparation of Stabilized Nanofluid Suspensions; McGill University: Montréal, QC, Canada, 2009.

43. Loos, M. Carbon Nanotube Reinforced Composites: CNT Polymer Science and Technologyp; Elsevier: Amsterdam, The Netherlands, 2014.

44. Hegab, H.; Umer, U.; Soliman, M.; Kishawy, H.A. Effects of nano-cutting fluids on tool performance and chip morphology during machining Inconel 718. Int. J. Adv. Manuf. Technol. 2018, 96, 3449-3458. [CrossRef]

45. Hegab, H.; Umer, U.; Soliman, M.; Kishawy, H. Performance evaluation of Ti-6Al-4V machining using nano-cutting fluids under minimum quantity lubrication. Int. J. Adv. Manuf. Technol. 2018, 95, 4229-4241. [CrossRef]

46. Eltaggaz, A.; Zawada, P.; Hegab, H.A.; Deiab, I. Coolant strategy influence on tool life and surface roughness when machining ADI. Int. J. Adv. Manuf. Technol. 2018, 94, 3875-3887. [CrossRef]

47. Hegab, H.; Kishawy, H.A.; Gadallah, M.H.; Umer, U.; Deiab, I. On machining of Ti-6Al-4V using multi-walled carbon nanotubes-based nano-fluid under minimum quantity lubrication. Int. J. Adv. Manuf. Technol. 2018, 97, 1593-1603. [CrossRef]

48. Kishawy, H.; Hegab, H.; Saad, E. Design for sustainable manufacturing: Approach, implementation, and assessment. Sustainability 2018, 10, 3604. [CrossRef]

49. Ghaednia, H.; Jackson, R.L. The effect of nanoparticles on the real area of contact, friction, and wear. J. Tribol. 2013, 135, 041603. [CrossRef]

(C) 2019 by the authors. Licensee MDPI, Basel, Switzerland. This article is an open access article distributed under the terms and conditions of the Creative Commons Attribution (CC BY) license (http://creativecommons.org/licenses/by/4.0/). 